Original

\title{
Daily low-intensity pulsed ultrasound stimulates production of bone morphogenetic protein in ROS 17/2.8 cells
}

\author{
Akito Suzuki ${ }^{1)}$, Tadahiro Takayama ${ }^{2)}$, Naoto Suzuki ${ }^{3,4)}$, Taro Kojima ${ }^{2)}$, Noriko Ota $^{2)}$, \\ Shoichi Asano $^{2)}$ and Koichi Ito ${ }^{2,5)}$ \\ ${ }^{1)}$ Division of Applied Oral Sciences, Nihon University Graduate School of Dentistry, Tokyo, Japan \\ ${ }^{2}$ Department of Periodontology, Nihon University School of Dentistry, Tokyo, Japan \\ ${ }^{3)}$ Department of Biochemistry, Nihon University School of Dentistry, Tokyo, Japan \\ ${ }^{4)}$ Division of Functional Morphology, Dental Research Center, Nihon University School of Dentistry, \\ Tokyo, Japan \\ ${ }^{5)}$ Division of Advanced Dental Treatment, Dental Research Center, Nihon University School of Dentistry, \\ Tokyo, Japan
}

(Received 31 October and accepted 7 November 2008)

\begin{abstract}
Although daily low-intensity pulsed ultrasound (LIPUS) can accelerate osteogenic differentiation of the rat clonal cell line ROS 17/2.8, the molecular mechanism that underlies this phenomenon is unclear. The purpose of this study was to determine which molecules exposed to daily LIPUS treatment stimulate osteogenic differentiation. The cells were cultured in the presence and absence (control) of LIPUS stimulation. LIPUS treatments consisted of $1.5-\mathrm{MHz}$ ultrasound administered at an intensity of $30 \mathrm{~mW} / \mathrm{cm}^{2}$, 20 min daily for 7 days. The expression of bone morphogenetic proteins (BMPs) and their receptors involved in osteogenesis were measured using realtime PCR and/or Western blot analysis. Phosphorylation of the mothers against decapentaplegic 1 (Smad1) protein was determined by Western blotting. Daily LIPUS treatment significantly increased the expression of BMP-2, -4 , and -7 and their receptors, and also phosphorylation of Smad1. Noggin markedly inhibited the daily LIPUS-induced phosphorylation of Smad1. Our findings demonstrate that the osteogenic activity of daily LIPUS may be mediated by BMPs in

Correspondence to Dr. Tadahiro Takayama, Department of Periodontology, Nihon University School of Dentistry, 1-8-13 Kanda-Surugadai, Chiyoda-ku, Tokyo 101-8310, Japan

Tel: +81-3-3219-8107

Fax: +81-3-3219-8349

E-mail: takayama@dent.nihon-u.ac.jp
\end{abstract}

ROS 17/2.8 cells. (J Oral Sci 51, 29-36, 2009)

Keywords: low-intensity pulsed ultrasound; ROS 17/2.8 cells; BMPs; Smad1; Noggin.

\section{Introduction}

Ultrasound has been used as a therapeutic, diagnostic, and surgical tool for a long time, and low-intensity pulsed ultrasound (LIPUS) stimulation is an established and widely used intervention for accelerating bone growth during fracture healing and distraction osteogenesis $(1,2)$. Moreover, LIPUS stimulation has been reported to accelerate bone maturation in animal models (3) and in clinical treatments (4).

In vitro experiments have demonstrated that LIPUS alters the differentiation pathway of the pluripotent mesenchymal cell line $\mathrm{C} 2 \mathrm{C} 12$ into an osteoblast and/or chondroblast lineage (5), and stimulates osteogenic differentiation in osteoblastic cells (6). We postulated that the effects of LIPUS treatment may be due to bone morphogenetic protein (BMP)-like molecules. The underlying mechanism responsible for the pronounced effects of daily LIPUS on osteogenesis, however, has not been fully elucidated.

BMPs are unique because they induce the differentiation of mesenchymal cells toward cells of the osteoblastic lineage and also enhance the differentiated function of the 
osteoblast $(7,8)$. BMPs bind to specific receptors and signal the cytoplasmic proteins mothers against decapentaplegic (Smad) 1 and 5 via phosphorylation. Smad 1 and 5 then form heterodimers with Smad4; these heterodimers undergo nuclear translocation and subsequently regulate transcription (9-12). In addition, the effects of BMPs can be modulated by a large number of secreted proteins that limit BMP action. Extracellular BMP antagonists prevent BMP signaling by binding BMPs, thus precluding their binding to specific cell surface receptors. These antagonists include noggin, chordin, and follistatin, which tend to be specific for, and are regulated by, BMPs, indicating the existence and need for local feedback mechanisms to temper BMP cellular activity (13-16).

To obtain insights into daily LIPUS treatment-induced bone formation, we investigated the effects of daily LIPUS treatment on the expression profiles of BMPs, BMP receptors, and phosphorylation of Smad1 in a rat osteosarcoma cell line.

\section{Materials and Methods \\ Cell culture}

We used the rat clonal cell line ROS 17/2.8 (ROS cells) (17) as the osteoblastic cell line. Although ROS cells were established from rat osteosarcoma, numerous studies have used these cells as typical rat osteoblasts or osteoblast-like cells (18-20). We therefore assumed that ROS cells represent the osteoblasts of alveolar bone in the periodontium. The cells were maintained in $\alpha$-minimal essential medium ( $\alpha$-MEM; Gibco BRL, Rockville, MD, USA) containing $10 \%(\mathrm{v} / \mathrm{v})$ heat-inactivated fetal bovine serum (FBS; HyClone Laboratories, Logan, UT, USA) and $1 \%(\mathrm{v} / \mathrm{v})$ penicillin-streptomycin solution (Sigma Chemical, St. Louis, MO, USA) at $37^{\circ} \mathrm{C}$ in a humidified atmosphere of $95 \%$ air and $5 \% \mathrm{CO}_{2}$.

\section{Ultrasound treatment}

ROS cells at the fifth or sixth passage were transferred into six-well microplates at a density of $2.0 \times 10^{4} \mathrm{cells} / \mathrm{cm}^{2}$. The cells were subjected to daily LIPUS with modifications, as reported previously $(21,22)$. Briefly, a sterilized transducer (Asahi Irika Co, Ltd., Saitama, Japan) generating $1.5-\mathrm{MHz}$ LIPUS in a pulsed-wave mode at $30 \mathrm{~mW} / \mathrm{cm}^{2}$ was placed horizontally into each culture well so that it was barely touching the surface of the medium. The distance between the transducer and the cells was 3-4 $\mathrm{mm}$. LIPUS stimulation was performed for 20 min daily up to 7 days, when the cells reached confluence. The culture medium was replaced with fresh medium once every 3 days. Control samples were treated in the same manner, without exposure to LIPUS.

\section{Real-time PCR}

ROS cells were plated in six-well microplates at a density of $2.0 \times 10^{4}$ cells $/ \mathrm{cm}^{2}$ and cultured for up to 7 days in the presence and absence (control) of LIPUS stimulation. On day 7 of daily LIPUS exposure, total RNA was isolated from the cultured cells using Trizol reagent (Invitrogen, Carlsbad, CA, USA) according to the manufacturer's instructions. Aliquots containing equal amounts of mRNA were subjected to real-time PCR analysis.

The amount of RNA was equalized using a human $\beta$ actin competitive PCR kit (Takara Shuzo, Shiga, Japan), and the mRNA was converted into cDNA using an RNA PCR kit (GeneAmp; Perkin-Elmer, Branchburg, NJ, USA). The resultant cDNA mixtures were diluted fivefold in sterile distilled water, and $2 \mathrm{ml}$ was subjected to real-time PCR using SYBR Green I dye (BioWhittaker Molecular Applications, Rockland, ME, USA). The reactions were performed in $25-\mu$ of a solution containing $1 \times \mathrm{R}$-PCR buffer, $1.5 \mathrm{mM}$ dNTP mixture, $1 \times$ SYBR Green I, $15 \mathrm{mM}$ $\mathrm{MgCl}_{2}, 0.25 \mathrm{U}$ Ex Taq R-PCR version (Takara Shuzo), and $20 \mathrm{mM}$ primers (sense and antisense; Table 1). The primers were designed using Primer3 software (Whitehead Institute for Biomedical Research, Cambridge, MA, USA).

Assays were performed on a Smart Cycler (Cepheid, Sunnyvale, CA, USA) and analyzed using Smart Cycler software (Ver. 1.2d). The PCR conditions were $95^{\circ} \mathrm{C}$ for $3 \mathrm{~s}$ and 40 cycles at $68^{\circ} \mathrm{C}$ for $20 \mathrm{~s}$. Measurements were taken at the end of each $68^{\circ} \mathrm{C}$ annealing step. PCR product specificity was verified by a melting curve analysis between 68 and $94^{\circ} \mathrm{C}$. All real-time PCR reactions were performed in triplicate, and the gene expression levels were normalized by dividing the calculated value for the mRNA samples by that for glyceraldehyde-3-phosphate dehydrogenase (GAPDH) mRNA at each time point.

\section{Extraction of proteins from the cultured cells}

To obtain whole-cell extracts, ROS 17/2.8 cells that had been cultured in the presence and absence (control) of LIPUS treatment were rinsed with phosphate-buffered saline (PBS) and exposed to a lysis buffer consisting of $50 \mathrm{mM}$ Tris- $\mathrm{HCl}, 0.1 \%$ Triton X-100, $0.1 \mathrm{mM}$ EDTA, and $1 \mathrm{mM}$ phenylmethylsulfonyl fluoride. The cells were then sonicated three times for $10 \mathrm{~s}$ each. Aliquots containing equal amounts of protein were subjected to sodium dodecyl sulphate-polyacrylamide gel electrophoresis (SDS-PAGE).

\section{SDS-PAGE and Western blotting}

Aliquots of the conditioned medium and whole-cell extracts containing equal amounts of protein were analyzed 
Table 1 Real-time polymerase chain reaction primers used in the experiments

\begin{tabular}{llcc}
\hline Target & Forward primer & Reverse primer & GenBank acc. no. \\
\hline BMPR-IA & 5'-TTATTCAGCTGCCTGTGGTCTGTGC-3' 5'-GGATTGTGGGCCCACTCATTCT-3' & NM_004329 \\
BMPR-IB & 5'-ATGTGGGCACCAAGAAG-3' & 5'-CTGCTCCAGCCCAATGCT-3' & NM_001203 \\
ActR-I & 5'-CTGGACCAGAGGAACAAAGG-3' & 5'-GGCGGGGTCTTACACGTCA-3' & NM_001105 \\
BMPR-II & 5'-AACATTTACAGAGTGCCTTTGATG-3' & 5'-AGCTGATTCACAGTCCCTCAAG-3' & NM_001204 \\
ActR-IIA & 5'-CGGGAAAATGGGAGCTGCTGC-3' & 5'-CAATCCCCGCAATTAACATAAGTG-3NM_001616 \\
ActR-IIB & 5'-GACACGGGAGTGCATCTACTAC-3' & 5'-GATGTCCACATGACCGTAGGG-3' & NM_001106 \\
GAPDH & 5'-AAATGGTGAAGGTCGGTGTG-3' & 5'-TGAAGGGGTCGTTGATGG-3' & NG_003018 \\
\hline
\end{tabular}

by SDS-PAGE on a 5-20\% gradient cross-linked polyacrylamide gel at $150 \mathrm{~V}$ for $60 \mathrm{~min}$. The discontinuous Tris-glycine buffer system of Laemmli was used for electrophoresis (23).

The separated proteins were immunotransferred to a membrane using a semidry transfer unit and a continuous buffer system at $0.8 \mathrm{~mA} / \mathrm{cm}^{2}$ constant amperage for 60 $90 \mathrm{~min}$. After the transfer was complete, the transfer membrane was treated with $25 \%$ (v/v) blocking reagent at $4{ }^{\circ} \mathrm{C}$ for $18 \mathrm{~h}$. The membranes were probed with 1:500 dilutions of antibodies against BMP-2, BMP-4, BMP-7, phosphorylated Smad1 (p-Smad1), and tubulin (all from Santa Cruz Biotechnology, Santa Cruz, CA, USA), followed by the addition of biotin-conjugated secondary antibodies (diluted 1:10,000) (24). The membranes were then treated with horseradish-peroxidase-conjugated streptavidin. Immunoreactive proteins were visualized using a chemiluminescence kit (Amersham LifeScience, Buckinghamshire, UK) with exposure to X-ray film. As a control, the transfer membrane was also exposed to normal rabbit serum at concentrations adjusted to match those of the primary antibodies.

Effect of daily LIPUS on protein and mRNA expression of BMPs and their receptors

ROS 17/2.8 cells were plated onto six-well microplates at a density of $2.0 \times 10^{4}$ cells/ well, and were then cultured in the presence and absence (control) of LIPUS for up to 7 days.
Effect of daily LIPUS on the phosphorylation of Smad1

ROS 17/2.8 cells were plated onto six-well microplates at a density of $2.0 \times 10^{4}$ cells/ well, and were then cultured in the presence and absence (control) of LIPUS for up to $30 \mathrm{~min}$ on day 7 .

Effect of noggin on daily LIPUS-induced Smad1 phosphorylation

ROS 17/2.8 cells in growth medium were plated onto six-well microplates at a density of $2.0 \times 10^{4}$ cells/well. The following day, the medium was exchanged for fresh medium and exposed to LIPUS daily, with or without 100 $\mathrm{ng} / \mathrm{ml}$ noggin (G-T, Minneapolis, MN, USA), after which the cells were incubated for up to $30 \mathrm{~min}$ on day 7 (to measure the phosphorylation of Smad1).

\section{Statistical analysis}

All data are represented as the mean \pm standard deviation (SD). The statistical significance was determined using Bonferroni's modification of Student's $t$-test. Values of $P$ $<0.05$ were considered to be statistically significant.

\section{Results}

Effect of daily LIPUS stimulation on BMP-2, 4 , and -7 protein expression

BMP-2, -4 , and -7 protein expression in nuclear extracts of cultured ROS 17/2.8 cells treated with daily LIPUS was examined using western blot analysis. An immunoreactive band was observed at $\sim 17, \sim 22$, and $\sim 20 \mathrm{kDa}$, which corresponded to BMP-2, -4 , and -7 , respectively (Fig. 1). 


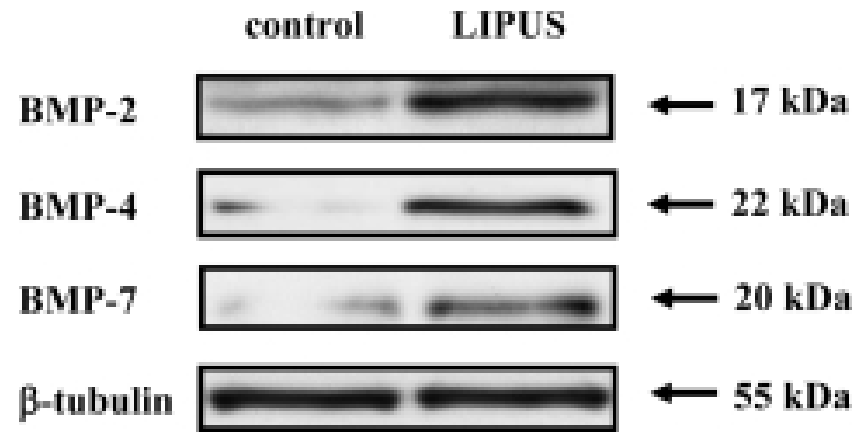

Fig. 1 Effect of daily LIPUS stimulation on BMP-2, -4, and -7 protein expression. The cells were cultured for 7 days in the presence and absence (control) of LIPUS stimulation. The expression of protein for BMP-2, -4, and -7 in ROS cells was determined by Western blot analysis of cells cultured for 7 days in the presence and absence of LIPUS stimulation.

\section{Effect of daily LIPUS stimulation on BMP receptor mRNA expression}

Of the BMP type I receptors, the ROS 17/2.8 cells expressed BMPR-IA, BMPR-IB, and ActR-I, irrespective of daily LIPUS stimulation. The mRNA expression of those three receptors increased significantly on day 7 of culture with daily LIPUS (Fig. 2a-c).

Of the BMP type II receptors, the cells expressed BMPRII, ActR-IIA, and ActR-IIB, in the presence and absence (control) of LIPUS treatment. The mRNA expression of those three receptors also increased significantly on day 7 of culture with daily LIPUS (Fig. 2d-f).

Effects of daily LIPUS on the phosphorylation of Smad1

The phosphorylation of Smad1 was evaluated using western blot analysis. An immunoreactive band at $\sim 65 \mathrm{kDa}$, which corresponded to phosphorylated Smad1 (p-Smad1),
BMPR-IA

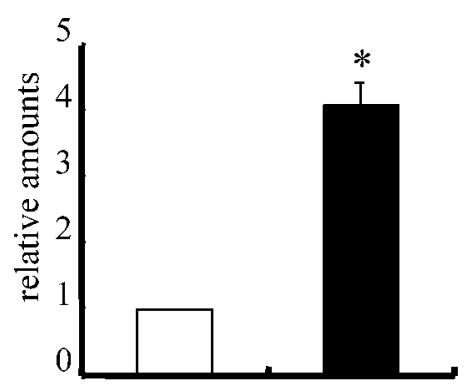

day 7

BMPR-II

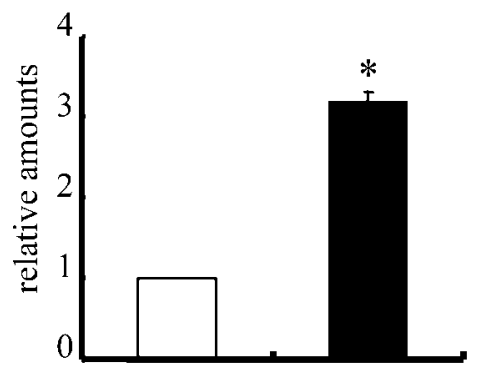

day 7
BMPR-IB

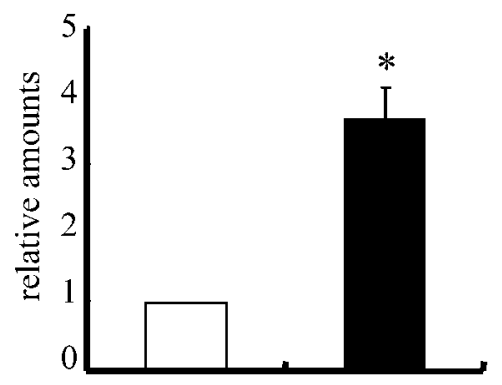

day 7

ActR-IIA

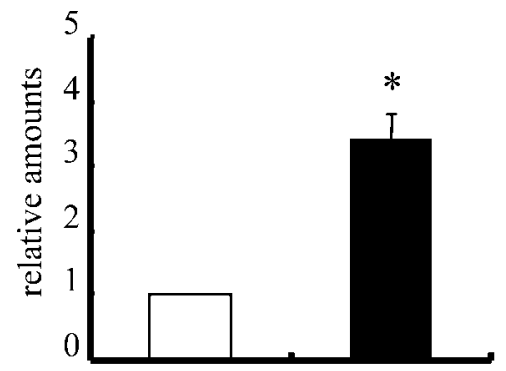

day 7
ActR-I

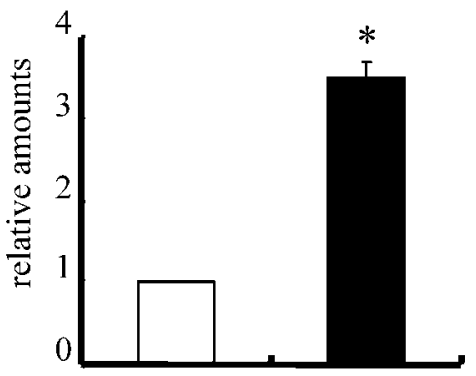

day 7

ActR-IIB

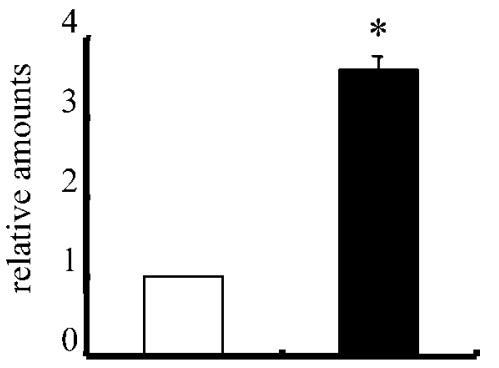

day 7

\section{control \\ LIPUS}

Fig. 2 Effect of daily LIPUS stimulation on BMP receptor mRNA expression. The cells were cultured for 7 days in the presence and absence (control) of LIPUS stimulation. The expression of the mRNA for BMPRIA, BMPR-IB, ActR-I, BMPR-II, ActR-IIA, and ActR-IIB was determined using real-time PCR. The data shown are the mean \pm SD of three separate experiments. $* P<0.05$ for LIPUS-treated versus control. 
was observed. With the addition of daily LIPUS treatment, the level of p-Smad1 progressively increased after 5-30 $\min$ (Fig. 3).

\section{Effect of noggin on daily LIPUS-induced Smad1 phosphorylation}

We used noggin to examine the specificity of the effect of daily LIPUS treatment on the p-Smad1 using Western blot analysis. The addition of $100 \mathrm{ng} / \mathrm{ml}$ noggin caused a marked inhibition of the daily LIPUS-induced p-Smad1 (Fig. 4).

\section{Discussion}

The central findings of the present study were that daily
LIPUS stimulated osteogenic differentiation via increased $\mathrm{BMP}$ production and $\mathrm{BMP}$ receptors.

The expression of BMPs, their antagonists, and transcription factors involved in osteogenesis is significantly increased by mechanical stress such as optimal compressive force (25) and shear stress (26). Although mechanical stress stimulates BMP production, no studies have investigated the effects of daily LIPUS treatment on BMP expression. We previously reported that daily LIPUS stimulation markedly increased the expression of BMP2 mRNA (27), and we postulated that these effects may be due to BMPs. The hypothesis of the present study was that daily LIPUS treatment would accelerate osteogenic differentiation via BMP expression. Consequently, we



Fig. 3 Effect of daily LIPUS stimulation on the phosphorylation of Smad1. The cells were cultured in the presence and absence (control) of LIPUS stimulation for up to $30 \mathrm{~min}$. Protein extracts from these cells were analyzed using Western blotting. Upper two panels: p-Smadlexpression; lower two panels: Smad1 expression.
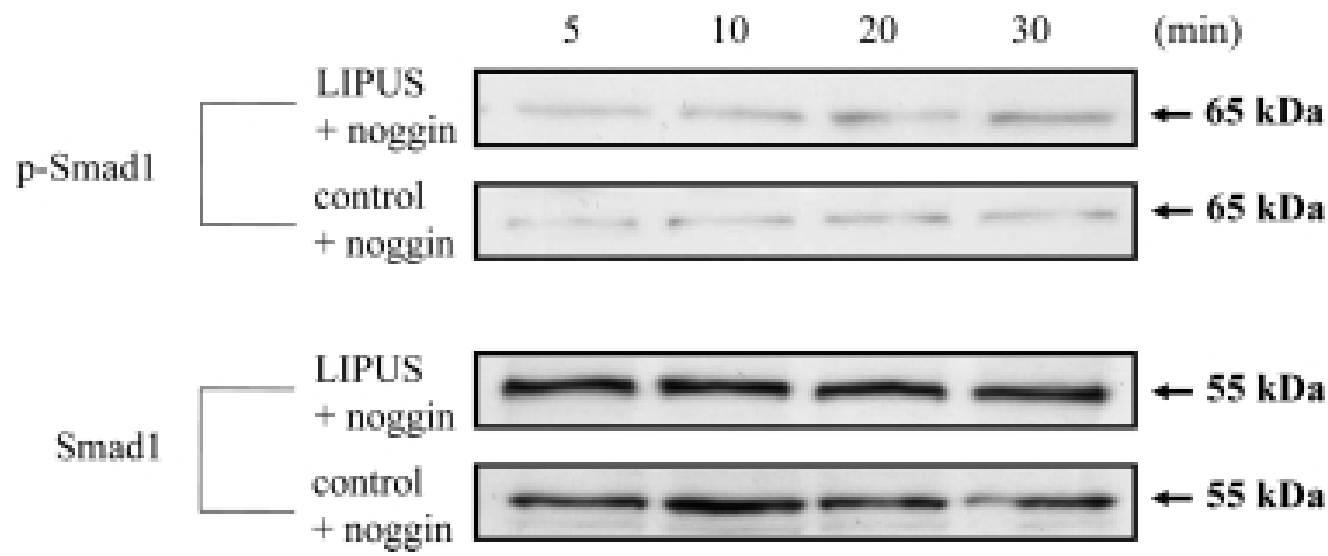

Fig. 4 Effect of noggin on daily LIPUS-induced Smad1 phosphorylation. The cells were cultured in the presence and absence (control) of LIPUS stimulation for up to $30 \mathrm{~min}$. Protein extracts from these cells were analyzed using Western blotting. Upper two panels: pSmad1expression; lower two panels: Smad1 expression. The phosphorylation of Smad1 after daily LIPUS treatment was blocked with $100 \mathrm{ng} / \mathrm{ml}$ noggin. 
investigated the effects of daily LIPUS treatment on BMP expression in detail.

BMPs can up-regulate $\mathrm{Cbfa} 1 / \mathrm{Run} \times 2 \mathrm{mRNA}$ expression in vitro. BMP-2, -4 , and -7 (members of the TGF- $\beta$ superfamily) are the primary growth factors that promote the differentiation of mesenchymal cells into osteoblasts or chondroblasts (28). BMP-2 increased Runx2 mRNA expression in an immortalized human bone marrow stromal cell line, hMC2-6 cells (29), C2C12 cells (30), and 2T3 cells (31). BMP-4 also stimulated osteoblastic differentiation of the mouse bone marrow stromal cell lines ST2 and MC3T3-G2/PA6 (32). BMP-7 induced the expression of Runx 2 mRNA prior to the induction of osteocalcin mRNA in C3H10T1/2, cells from early mouse embryos (33). Based on these studies, we examined the effect of daily LIPUS treatment on BMP-2, -4 , and -7 protein expression. Our results indicated that daily LIPUS treatment caused a substantial increase in expression of all BMP proteins. These results suggest that daily LIPUS treatment promotes osteogenic differentiation of ROS cells.

As BMP binds specific receptors (33), the effects of daily LIPUS on the expression of BMP receptors were examined. Our results demonstrated that both type I receptors (BMPRIA, BMPR-IB, and ActR-I) and type II receptors (BMPRII, ActR-IIA, and ActR-IIB) were significantly increased by daily LIPUS treatment. These results were observed irrespective of their subfamily. In addition, these results suggest that daily LIPUS treatment accelerates the autocrine action of BMPs.

Evidence exists of the autoregulation of BMP expression in osteoblasts, which acts as a negative feedback loop to decrease cellular exposure to BMPs. These protective mechanisms do not appear to be sufficient, and much of the regulation of BMP action occurs through the presence of intercellular and extracellular factors that modulate BMP activity (34). Numerous antagonists of BMP have been identified, including noggin, follistatin, and chordin (35). All BMP antagonists share the functional property of specifically binding BMPs to prevent them from interacting with their receptors $(35,36)$. Noggin is known to inhibit the functions of BMP-2, BMP-4, and BMP-7 (35). Thus, in this study, we examined the effect of noggin on the phosphorylation of Smad1. We found that noggin markedly inhibited daily LIPUS-induced phosphorylation of Smad1. These results strongly suggest that the phosphorylation of Smad1 enhanced by daily LIPUS is a result of the autocrine action of daily LIPUS-induced BMP expression.

In conclusion, we showed that daily LIPUS treatment significantly increased the expression of the BMP-2, -4 , and -7 proteins and Smad1 phosphorylation, and the phosphorylation of Smad1 can be blocked by the BMP antagonist, noggin. Therefore, osteogenic activity of daily LIPUS may be mediated by BMPs.

\section{Acknowledgments}

We wish to thank Asahi Irika Co., Ltd., especially Mr. Shigejyu Kaji, for providing the ultrasound transducer. This study was supported by a multidisciplinary research project grant from the Ministry of Education, Culture, Sports, Science and Technology of Japan and by a grant from the Dental Research Center at the Nihon University School of Dentistry. The promotion and Mutual Aid Corporation for Private Schools of Japan also provided support for this study.

\section{References}

1. Cook SD, Ryaby JP, McCabe J, Frey JJ, Heckman JD, Kristiansen TK (1997) Acceleration of tibia and distal radius fracture healing in patients who smoke. Clin Orthop Relate Res 337, 198-207.

2. Schortinghuis J, Bronckers AL, Stegenga B, Raghoebar GM, de Bont LG (2005) Ultrasound to stimulate early bone formation in a distraction gap: a double blind randomized clinical pilot trial in the edentulous mandible. Arch Oral Biol 50, 411-420.

3. Mayer E, Laule A, Suger G, Ruter A, Claes L (2001) Radiographic results of callus distraction aided by pulsed low-intensity ultrasound. J Orthop Trauma $15,407-414$

4. El-Mowafi H, Mohsen M (2005) The effect of lowintensity pulsed ultrasound on callus maturation in tibial distraction osteogenesis. Int Orthop 29, 121124.

5. Ikeda K, Takayama T, Suzuki N, Shimada K, Otsuka k, Ito K (2006) Effects of low-intensity pulsed ultrasound on the differentiation of $\mathrm{C} 2 \mathrm{C} 12$ cells. Life Sci 79, 1936-1943.

6. Takayama T, Suzuki N, Ikeda K, Shimada T, Suzuki A, Maeno M, Otsuka K, Ito K (2007) Low-intensity pulsed ultrasound stimulates osteogenic differentiation in ROS 17/2.8 cells. Life Sci 80, 965-971.

7. Rosen V, Wozney JM (2001) Bone morphogenetic proteins. In: Principles of bone biology, 2nd ed, Bilezikian JP, Raisz LG, Rodan GA eds, Academic Press, Cambridge, 919-928.

8. Wozney JM, Rosen V, Celeste AJ, Mitsock LM, Whitters MJ, Kriz RW, Hewick RM, Wang EA (1988) Novel regulators of bone formation: molecular clones and activities. Science 242, 1528- 
1534.

9. Derynck R, Zhang Y, Feng XH (1998) Smads: transcriptional activators of TGF-beta responses. Cell 95, 737-740.

10. Kretzschmar M, Massague J (1998) SMADs: mediators and regulators of TGF- $\beta$ signaling. Curr Opin Genet Dev 8, 103-111.

11. Liu F, Ventura F, Doody J, Massague J (1995) Human type áU receptor for bone morphogenetic proteins (BMPs): extension of the two-kinase receptor model to the BMPs. Mol Cell Biol 15, 3479-3486.

12. Yamashita H, Ten Dijke P, Heldin CH, Miyazono K (1996) Bone morphogenetic protein receptors. Bone 19, 569-574.

13. Graff JM (1997) Embryonic patterning: to BMP or not to BMP, that is the question. Cell 89, 171-174.

14. Iemura S, Yamamoto TS, Takagi C, Uchiyama H, Natsume T, Shimasaki S, Sugino H, Ueno N (1998) Direct binding of follistatin to a complex of bonemorphogenetic protein and its receptor inhibits ventral and epidermal cell fates in early Xenopus embryo. Proc Natl Acad Sci USA 95, 9337-9342.

15. Zhang D, Ferguson CM, O'keefe RJ, Puzas JE, Rosier RN, Reynolds PR (2002) A role for the BMP antagonist chordin in endochondral ossification. J Bone Miner Res 17, 293-300.

16. Zimmerman LB, De Jesus-Escobar JM, Harland RM (1996) The Spemann organizer signal noggin binds and inactivates bone morphogenetic protein 4. Cell 86, 599-606.

17. Majeska RJ, Nair BC, Rodan GA (1985) Glucocorticoid regulation of alkaline phosphatase in the osteoblastic osteosarcoma cell line ROS 17/2.8. Endocrinology 116, 170-179.

18. Yoon K, Golub E, Rodan GA (1989) Alkaline phosphatase cDNA transfected cells promote calcium and phosphate deposition. Connect Tissue Res 22, 17-25.

19. Jheon AH, Suzuki N, Nishiyama T, Cheifetz S, Sodek J, Ganss B (2003) Characterization of the 5'flanking region of the rat AJ18 gene. Gene 310, 203213.

20. Shimizu E, Nakajima Y, Kato N, Nakayama Y, Saito R, Samoto H, Ogata Y (2004) Regulation of rat bone sialoprotein gene transcription by enamel matrix derivative. J Periodontol 75, 260-267.

21. Reher P, Harris M, Whiteman M, Hai HK, Meghji S (2002) Ultrtasound stimulates nitric oxide and prostaglandin $\mathrm{E}_{2}$ production by human osteoblasts. Bone 31, 236-241.
22. Hayton MJ, Dillon JP, Glynn D, Curran JM, Gallagher JA, Buckley KA (2005) Involvement of adenosine 5'-triphosphate in ultrasound-induced fracture repair. Ultrasound Med Biol 122, 49-60.

23. Laemmli UK (1970) Cleavage of structural proteins during the assembly of the head of bacteriophage T4. Nature 227, 680-685.

24. Chen JK, Zhang Q, McCulloch CA, Sodek J (1991) Immunohistochemical localization of bone sialoprotein in foetal porcine bone tissues: comparisons with secreted phosphoprotein 1 (SRP1, osteopontin) and SPARC (osteonectione). Histochem J 23, 281-289.

25. Mitsui N, Suzuki N, Maeno M, Yanagisawa M, Koyama Y, Otsuka K, Shimizu N (2006) Optimal compressive force induces bone formation via increasing bone morphogenetic proteins production and decreasing their antagonists production by Saos2 cells. Life Sci 78, 2697-2706.

26. Hsieh PC, Kenagy RD, Mulvihill ER, Jeanette JP, Wang X, Chang CM, Yao Z, Ruzzo WL, Justice S, Hudkins KL, Alpers CE, Berceli S, Clowes AW (2006) Bone morphogenetic protein 4: potential regulator of shear stress-induced graft neointimal atrophy. J Vasc Surg 43, 150-158.

27. Suzuki A, Takayama T, Suzuki N, Sato M, Fukuda T, Ito K (2008) Daily low-intensity pulsed ultrasound mediated osteogenic differentiation in rat osteoblasts. Acta Biochim Biophys Sin (in press).

28. Wright E, Hargrave MR, Christiansen J, Cooper L, Kun J, Evans T, Gangadharan U, Greenfield A, Koopman P (1995) The Sry-related gene Sox9 is expressed during chondrogenesis in mouse embryos. Nature Genetics 9, 15-20.

29. Gori F, Thomas T, Hicok KC, Spelsberg TC, Riggs BL (1999) Differentiation of human marrow stromal precursor cells: bone morphogenetic protein-2 increases OSF2/CBFA1, enhances osteoblast commitment, and inhibits late adipocyte maturation. J Bone Miner Res 14, 1522-1535.

30. Lee MH, Javed A, Kim HJ, Shin HI, Gutierrez S, Choi JY, Rosen V, Stein JL, van Wijnen AJ, Stein GS, Lian JB, Ryoo HM (1999) Transient upregulation of CBFA1 in response to bone morphogenetic protein-2 and transforming growth factor beta1 in $\mathrm{C} 2 \mathrm{C} 12$ myogenic cells coincides with suppression of the myogenic phenotype but is not sufficient for osteoblast differentiation. J Cell Biochem 73, 114-125.

31. Chen D, Ji X, Harris MA, Feng JQ, Karsenty G, Celeste AJ, Rosen V, Mundy GR, Harris SE (1998) 
Differential roles for bone morphogenetic protein (BMP) receptor type áTB and áTA in differentiation and linages. J Cell Biol 142, 295-305.

32. Yamaguchi A, Ishizuya T, Kintou N, Wada Y, Katagiri T, Wozney JM, Rosen V, Yoshiki S (1996) Effects of BMP-2, BMP-4, and BMP-6 on osteoblastic differentiation of bone marrow-derived stromal cell lines, ST2 and MC3T3-G2/PA6. Biochem Biophys Res Commun 220, 366-371.

33. Ducy P, Zhang R, Geoffroy V, Ridall AL, Karsenty G (1997) Osf2/Cbfa1: a transcriptional activator of osteoblast differentiation. Cell 89, 747-754.

34. Canalis E, Economides AN, Gazzerro E (2003) Bone morphogenetic proteins, their antagonists, and the skeleton. Endocr Rev 24, 218-235.

35. Miyazono K (2000) Positive and negative regulation of TGF- $\beta$ signaling. J Cell Sci 113, 1101-1109.

36. Iemura S, Yamamoto TS, Takagi C, Kobayashi H, Ueno N (1999) Isolation and characterization of bone morphogenetic protein-binding proteins from the early Xenopus embryo. J Biol Chem 274, 2683426849. 